Article

\title{
Risk Prediction Model Development for Late On-Set Breast Cancer Screening in Low- and Middle-Income Societies: A Model Study for North Cyprus
}

\author{
Ceasar Dubor Danladi ${ }^{1}$ and Nedime Serakinci ${ }^{2,3, *}$ \\ 1 Department of Medical Genetics, Institute of Health Sciences, Near East University, Nicosia 99138, \\ Turkish Republic of North Cyprus; 20167382@std.neu.edu.tr \\ 2 Department of Medical Genetics, Faculty of Medicine, Near East University, Nicosia 99138, \\ Turkish Republic of North Cyprus \\ 3 Department of Molecular Biology and Genetics, Faculty of Art and Sciences, Near East University, \\ Nicosia 99138, Turkish Republic of North Cyprus \\ * Correspondence: nedime.serakinci@neu.edu.tr; Tel.: +90-392-675-1000
}

Received: 26 May 2020; Accepted: 6 July 2020; Published: 16 July 2020

\begin{abstract}
Background: Early detection of breast cancer alters the prognosis and tools that can predict the risk for breast cancer in women will have a significant impact on healthcare systems in lowand middle-income regions, such as North Cyprus. Objective: In this study, we developed a simple breast cancer risk model for the women of North Cyprus. Methods: Data from 655 women, consisting of 318 breast cancer cases and 337 hospital-based controls, was used to develop and internally validate the model, external validation was carried out using, 653 women consisting of 126 cases and 527 controls. Data were obtained from medical records and interviews after informed consent. Results: A model was derived that consisted of age $\geq 50$ years and $<50$ years and the presence and absence of $>1$ first-degree relatives (FDR) with breast cancer. From internal and external validations the model's AUCs were, $0.66(95 \% \mathrm{CI}=0.62-0.70)$ and $0.69(95 \% \mathrm{CI}=0.63-0.74)$ respectively. Conclusions: A unique model for risk prediction of breast cancer was developed to aid in identifying high-risk women from North Cyprus that can benefit from mammogram screening. Further study on a large scale that includes environmental risk factors is warranted.
\end{abstract}

Keywords: breast cancer; mammogram; risk prediction model; North Cyprus

\section{Introduction}

Breast cancer is a disease that has remained the leading cause of death in women worldwide [1]. In 2018, over two million women were diagnosed with breast cancer in 140 of 184 nations [2]. Breast cancer incidence and deaths occur mostly in low- and middle-income countries [3,4]. One-half of all breast cancer cases exist in low- and middle-income societies, with $62 \%$ of the world's breast cancer deaths [5], whereas in the United States, approximately 268,600 new cases of breast cancer are diagnosed each year, and the mortality rate is decreasing [6], with $89.7 \%$ five-year survival rate [1,7]. These portray inequality in global health standards.

Additionally, the prognosis is always poor for women living in low- and middle-income countries $[7,8]$, because of lack of risk forecast, late detection, late intervention, environmental factors and lack of education on routine care.

Northern Cyprus, can be regarded as a middle-income society, small, enclosed, ideal for epidemiological research, has a typical western Mediterranean lifestyle, with living conditions and diets that should be favorable for good health $[9,10]$. Previously, Hincal et al. investigated the prevalence of cancer in Northern Cyprus, compared to different European countries between 1990 and 
2004, and showed that breast cancer was the most common cancer in women and diagnosed at a lower average age than Northern and Southern Europe [11]. Later on, Pervaiz et al. also found that out of 1395 enlisted cancer cases between 2007 and 2012, 665 (47.67\%) were women, and breast cancer was the most common cancer type among the women [12]. The lifespan of women in the developing world is increasing, and thus many more women are reaching an age where breast cancer rates are high [13].

In high-income countries, the incidence and mortality associated with breast cancer are decreasing. These may be accounted for because of access to mammogram screening, effective health services, and good execution of breast cancer prevention campaigns, as well as primary prevention policies and guidelines [14-16]. Yet the burden on healthcare systems is increasing in low- and middle-income countries.

Despite the fact, mammogram screening has been supported for the early detection of breast cancer, it is not cost-effective and feasible for developing countries, because of the large population of women, underfunding, infrastructure and human expertise needed [16-24]. Therefore, such countries can benefit from cost-effective and efficient risk assessment screening strategies, which do not depend on tertiary or specialized healthcare. Denny et al. explored some cost-effective methods that can be used to reduce the gap between developing countries and developed countries for breast cancer early detection, prevention, and care [25].

Risk prediction models can be used to identify high-risk women that will be eligible for mammogram screening. Thus, reducing the overload on the limited facilities available and narrowing the focus on the appropriate group can also reduce administering unnecessary radiation to women, who are not eligible, while at the same time reducing the economic burden on the government. Currently, several comprehensive breast cancer risk assessment tools exist that incorporate various risk factors for the calculation of breast cancer risk [1].

Many risk factors play a role in the development of breast cancer. Environmental factors that contribute to interethnic variations in risk, age, lifestyle factors, endogenous and exogenous hormonal exposure, childbearing, breastfeeding, reduced physical activity, dietary consumption, certain reproductive factors (low parity, late age at first pregnancy), body size/obesity contribute to differences in incidence [26], family history and genetic influence are particularly strong risk factors for breast cancer [27,28] and breast density, which is also a predictor for breast cancer [29].

Breast cancer risk assessment models are categorized into empirical models or genetic models [30]. A pattern of genetic inheritance of breast cancer risk is considered by the genetic models. Several risk assessment models have been proposed [30-32]. The Breast and Ovarian Analysis of Disease Incidence and Carrier Estimation Algorithm (BOADICEA) model includes a polygenic component, which allows for the familial correlation that is not captured by mutations in Breast Cancer genes (BRCA) 1 or 2 [33], while the International Breast Cancer Intervention Study (IBIS) model, accommodates such residual familial correlation by incorporating a latent common autosomal dominant low-risk gene [34]. The National Cancer Institute's Breast Cancer Risk Assessment Tool (BCRAT) also known as the "Gail Model" [35], estimates risk by incorporating the familial influence of first-degree relatives with breast cancer. The models are known for better performances in predicting high-risk women in the regions, which they were developed [36]. The development of a breast cancer risk model for the women of North Cyprus will allow for the early identification of high-risk women that will lead to early preventive interventions [37] and will save lives.

\section{Materials and Methods}

This study was carried out in the hospital, Burhan Nalbantoglu Devlet Hastanesi, Lefkosa, North Cyprus. This hospital treats all breast cancer cases in North Cyprus. Ethical approvals were obtained from Near East University, scientific research evaluation ethics committee, and Burhan Nalbantoglu Devlet Hastanesi's ethics committee, before the research was carried out (YDU/2018/55-523). All methods were performed following the relevant guidelines and regulations. 


\subsection{Study Population}

The retrospective dataset of 655 women, collected from April 2018 to December 2018, was used to derive the model. A total of 318 women had newly confirmed breast cancer, and 337 women were without breast cancer. Women with a history of lobular or ductal carcinoma in-situ were excluded. Only participants between the ages of 30 to 84 years were included in the whole study groups. Informed consent to participate was obtained after the aims of the study were explained by a medical professional.

\subsection{Data Collection:}

Retrospective medical and demographic information of all participants were collected through interviews.

The interview included: age, age at menarche, age at first delivery, menopausal status, presence or absence of benign breast disease, history of breast cancer in first-degree relatives or other relatives, history of hormone replacement therapy including estrogen/progestin and breast density.

Sampling size was based on the following calculations:

$$
n=\frac{N \times t^{2} p \times q}{(N-1) d^{2}+t^{2} \times p \times q}
$$

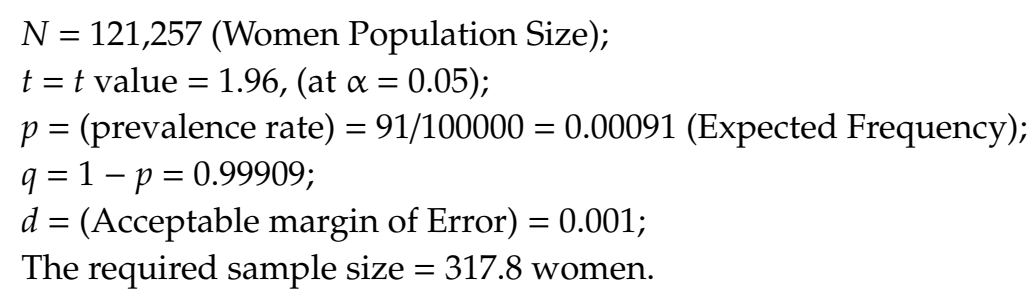

\subsection{Statistical Analysis}

The frequency of the risk factors of the study group was analyzed using descriptive statistics. An initial multivariable logistic regression was carried out. The significant variables were considered for further multivariable logistic regression. A forward multivariable logistic regression was used to access the final model. In the multivariable regression analysis, the categories that conferred protection against breast cancer were used as the reference. All statistical analysis was performed with IBM Spss (IBM, Armonk, NY, USA).

\subsubsection{Internal Validation}

The whole dataset of 655 women, consisting of 318 breast cancer cases and 337 without breast cancer from the derived phase, was used to internally validate the model using bootstrap with 200 repetitions [38,39]. For each bootstrap, the derived model was fitted and the risk of breast cancer was estimated. The correlation between the observed and predicted values of breast cancer was estimated in the bootstrap data (called Dboot) and derived data (called Doriginal) using the Somer' $\mathrm{D}$ coefficient [38]. The optimism bias was assessed by subtracting Doriginal from Dboot.

\subsubsection{External Validation}

Separate information of 653 women, consisting of 126 cancer cases and 527 women without breast cancer, collected between November 2018 to January 2020, were used to externally validate the model. Total scores for individuals were calculated based on the derived scoring scheme, and the c-statistic was then estimated. 


\section{Results}

A total of 655 women were used to derive the model. Among them, 51.1\% were above 50 years; $48.5 \%$ (318) of the women had breast cancer, while the rest reported with no breast cancer. A > 1 FDR with breast cancer was reported in $9.9 \%$ of the study population (Table 1 ).

Table 1. The frequencies and percentages of variables in the datasets used for the model development.

\begin{tabular}{|c|c|}
\hline Characteristics & Frequencies (\%) \\
\hline \multicolumn{2}{|l|}{ Reproductive History } \\
\hline \multicolumn{2}{|l|}{ Age at menarche } \\
\hline$\geq 14$ years & $155(23.7 \%)$ \\
\hline $14-13$ years & $421(64.3 \%)$ \\
\hline$>12-<13$ years & $0(0 \%)$ \\
\hline$<12$ years & $79(12.1 \%)$ \\
\hline \multicolumn{2}{|l|}{ Age at first birth } \\
\hline$\geq 30$ years & $58(8.9 \%)$ \\
\hline $25-29$ years & $142(21.7 \%)$ \\
\hline 20-24 years & $238(36.3 \%)$ \\
\hline$<20$ years & $167(25.5 \%)$ \\
\hline Nulliparous & $50(7.8 \%)$ \\
\hline \multicolumn{2}{|l|}{ Menopausal status } \\
\hline Premenopausal & $314(47.9 \%)$ \\
\hline Perimenopausal & $13(2.0 \%)$ \\
\hline Postmenopausal & $328(50.1 \%)$ \\
\hline \multicolumn{2}{|l|}{ Breastfeeding } \\
\hline$\geq 24$ months & $285(43.5 \%)$ \\
\hline$<24->18$ months & $0(0 \%)$ \\
\hline $18-12$ months & $236(36.0 \%)$ \\
\hline$<12->6$ months & $0(0 \%)$ \\
\hline$<6$ months & $83(12.7 \%)$ \\
\hline Never & $51(7.8 \%)$ \\
\hline \multicolumn{2}{|l|}{ Breast density } \\
\hline Extremely dense & $58(8.9 \%)$ \\
\hline Heterogeneously dense & $334(51.0 \%)$ \\
\hline Almost entirely fatty & $263(40.2 \%)$ \\
\hline \multicolumn{2}{|l|}{ Demographic Data } \\
\hline \multicolumn{2}{|l|}{$>1$ First degree relatives } \\
\hline Yes & $65(9.9 \%)$ \\
\hline No & $590(90.1 \%)$ \\
\hline \multicolumn{2}{|l|}{ Second degree relatives } \\
\hline Yes & $41(6.3 \%)$ \\
\hline No & $614(93.7 \%)$ \\
\hline \multicolumn{2}{|c|}{ Hormone Replacement Therapy } \\
\hline Yes & $17(2.6 \%)$ \\
\hline No & $638(97.4 \%)$ \\
\hline \multicolumn{2}{|l|}{ Breast biopsy } \\
\hline Yes & $85(13.0 \%)$ \\
\hline No & $570(87.0 \%)$ \\
\hline \multicolumn{2}{|l|}{ Age } \\
\hline$>50$ & $320(48.9 \%)$ \\
\hline$\leq 50$ & $335(51.1 \%)$ \\
\hline \multicolumn{2}{|l|}{ Disease status } \\
\hline Breast cancer cases & $318(48.5 \%)$ \\
\hline Without breast cancer & $337(51.5 \%)$ \\
\hline
\end{tabular}


A total of 10 variables were analyzed to access the risk model, After an initial logistic regression of all the variables and two successive forward multivariable logistic regression, the risk factors that were observed to be insignificant were eliminated at each step, then we arrived at two significant risk predictors that comprised the final model, that is $>1$ FDR with breast cancer OR $=3.0(95 \% \mathrm{CI}$ 1.6-5.4) and age above 50 years $\mathrm{OR}=3.0(95 \%$ CI 2.2-4.1). The c-statistic of the final model on internal validation was 0.66 (95\% CI 0.62-0.70). The estimated coefficients of the two variables served as the basis for the scoring with a range of $0-2$. The risk scores were stratified into three groups; low-risk (0) women $<50$ years and with no $>1$ FDR with breast cancer, moderate-risk (1) women with $>1$ FDR with breast cancer or $\geq 50$ years and high-risk (2)—that is, women $-\geq 50$ years and with $>1$ FDR with breast cancer.

From the internal validation the average Doriginal and Dboot were $(0.328)$ and $(0.350)$ respectively. The bias or optimism was (0.022).

Separate information from 653 women, was used for external validation, consisting of 126 women with breast cancer and 527 women without breast cancer. From Figure 1, the c-statistics was 0.69 (95\% CI 0.63-0.74), and the sensitivity and specificity are as shown in Table 2.

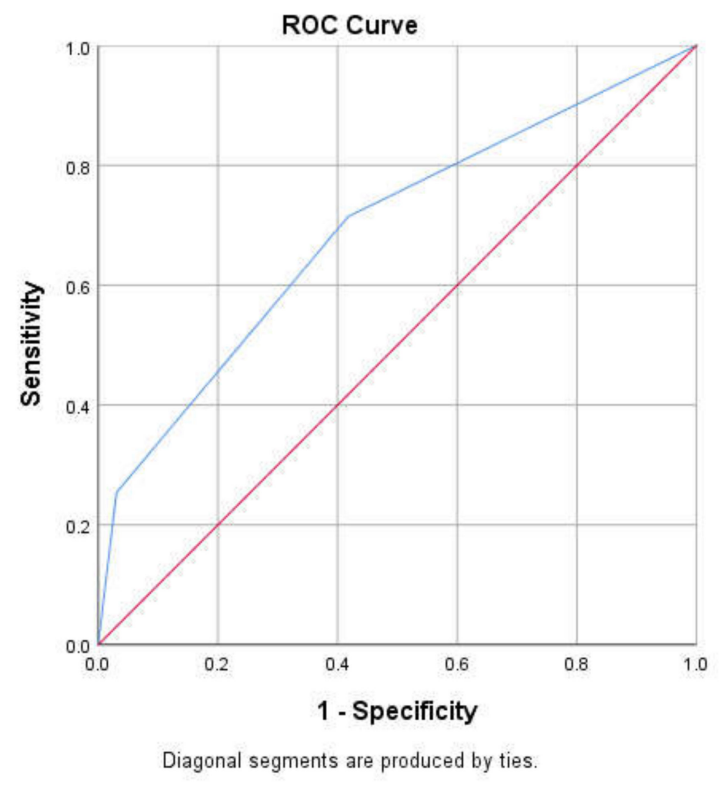

Figure 1. The receiver operating characteristics (ROC) curve of the simple model. This shows the discriminatory accuracy of the model. A value of 1 indicates perfect discrimination while 0.5 is by chance going to discriminate which woman will or will not have breast cancer. The red diagonal line represents the reference point. The blue line is the ROC curve of the simple model.

Table 2. Sensitivity and specificity of the simple model on external validation.

\begin{tabular}{ccc}
\hline Cut-Off Value & Sensitivity & Specificity \\
\hline $0.5-1.0$ & $71.4 \%$ & $41.7 \%$ \\
\hline
\end{tabular}

\section{Discussions}

In comparison, to a recent validation study carried out on a large cohort, the model showed similar c-statistics, sensitivity, and specificity to the Gail, IBIS and BOADICEA models [40]. The other models were developed for populations with base-line etiological risk factors that differed from our setting [36]. So, the model was developed to include only the base-line risk factors that are peculiar to the women of North Cyprus at the moment. Yet, the model can aid in categorizing high-risk women. The model utilized age $\geq 50$ years and $<50$ years and presence or absence of $>1$ FDR with breast cancer in determining the risk of breast cancer. 
Inherited factors elucidate just about a quarter of breast cancer risk [41]. Meta and pooled studies have demonstrated that breast cancer risk is around twice higher in women with one FDR with breast cancer than women with no FDR with breast cancer. The risk increases with a large number of affected FDR or other relatives affected under 50 years [42-44]. BRCA 1 and 2 mutations explain the molecular pathogenesis behind $15-20 \%$ of cases with FDR with breast cancer [41,45] and about $80-85 \%$ are as a result of genetic mutations that occur due to the aging process and lifestyle-related risk factors [42,46-56].

Aging plays a role in the pathogenesis of breast cancer because of genetic instability, telomere attrition, epigenetic alteration, stem cell exhaustion associated with aging.

From 50 years to 70 years and above, the risk of breast cancer increases [57].

The assessment of risk is vital for the management of breast cancer. High-risk women will not automatically have breast cancer, but they are strongly advised to visit cancer clinics. They should have a mammogram at least yearly, for this has been shown to increase detection rates and reduce mortality [58-62].

We recommend that the women of North Cyprus categorized as high-risk for breast cancer can benefit from regular monitoring using mammograms, early detection, and preventive interventions such as healthy lifestyle and medication.

Those women with moderate-risk of breast cancer, should undergo screening of breast cancer risk using mammograms biennially. For women above 50 years with no $>1$ FDR with breast cancer, while those women below 50 years with $>1$ FDR with breast cancer can consider the use of medications, such as tamoxifen or raloxifene to reduce the risk of developing breast cancer. Risk and benefits have to be assessed by a medical professional.

Low-risk women are required to indulge in primary care since their risk is not different from the general population, but this status is liable to change in the presence of modifiable risk factors. Thus, these women are encouraged to maintain a healthy lifestyle and breast care. Increased awareness of existing and identified risk factors will aid in evaluating their current status and make the appropriate decision for mammogram screening if warranted. These recommendations are summarized in Table 3.

Table 3. Summarized recommended guidelines for the management of breast cancer risk screened by the simple model in the women of North Cyprus.

\begin{tabular}{ccc}
\hline Risk Status & Suggestions/Advice & Outcome \\
\hline $\begin{array}{c}\text { High-risk } \\
(>1 \text { FDR and } \geq 50 \text { years })\end{array}$ & $\begin{array}{c}\text { Regular monitoring, early detection and } \\
\text { preventive interventions }\end{array}$ & Reduced mortality \\
\hline $\begin{array}{c}\text { Moderate-risk } \\
(>1 \text { FDR } \text { or } \geq 50 \text { years })\end{array}$ & Further screening to access risk & Prevention of occurrence \\
\hline $\begin{array}{c}\text { Low-risk } \\
(\text { No FDR },<50 \text { years })\end{array}$ & Primary care & Awareness and prevention \\
\hline
\end{tabular}

This model can serve as a simple, noninvasive, alternative screening for the identification of high-risk women, thus streamlining the focus of the limited mammogram resources to the right group in low- and middle-income countries such as North Cyprus. Using this model will also reduce unnecessary mammograms needed and radiation exposure to potentially low-risk women. The use of the risk prediction model has additional advantages, as it is not dependent on physical examination, easy to utilize and implement, being cost-effective and will enhance outcome and survival for women categorized as high-risk.

The poor funding of health systems in low- and middle-income countries causes problems in the implementation of mammogram screening programs, thereby leaving many of the women out and only a few from the urban centers with insurance policies are privileged to participate.

This model can serve as additional screening tools that will aid in identifying women at high-risk that will need an immediate mammogram, thus reducing the burden on the already constrained facilities and hence saving lives. 
The progress in mobile internet services in low- and middle-income countries has made online materials easily accessible to everyone. Educating and empowering women on how to use the risk prediction tools online will drastically reduce the number of high-risk women that cannot have access to early detection facilities. These will protect more women at the individual and population levels.

This initiative is maybe similar to the mobile health (mhealth) initiative launched by the world health organization in 2012, whereby mobile phones were used to improve the prevention, detection, and management of diseases in low-income countries [63]. The risk assessment model can be incorporated into the mhealth features, thereby empowering women. Low-risk women through mhealth, can benefit from primary care, where healthcare teams deliver healthcare remotely, through audio, video and text.

Risk prediction tools at the moment can serve as cost-saving tools. However, the benefits can only be maximized when all identified high-risk women can receive further confirmation screening and treatment. Therefore, identified high-risk women will still need to visit healthcare centers for counseling and prophylactic treatment.

While the models intend to ascertain the risk for an individual, the risk factors utilized to depend on population risk from epidemiological investigations. Therefore, more studies have to be carried out among various populations of women in other to identify new lifestyle/environmental factors, biomarkers, genetic markers and incidence rates that are peculiar to that group, which can be incorporated into prospective risk models because the possibility of identifying those at high-risk would be enhanced by using a comprehensive risk model that integrates all known risk factors [64]. Because our enrollment of breast cancer patients for this investigation is not specifically aimed to gather the early on-set breast cancer patients, we assume that our model is more suitable for the late on-set breast cancer risk prediction. That is why we added the phrase "Late On-Set Breast Cancer Screening" into the manuscript's title. We think that the early on-set breast cancer risk prediction model should be developed in the future by using a specific cohort made up by enrollment of early on-set breast cancer patients.

The weakness of our study is the fact that it was based on retrospectively collected data. However, the collecting process was done independently, so unlikely to have altered the results and caused bias. The AUC estimates are bound to be biased since our validation was carried out on a case-control group, but this was minimized [64]. The internal and external validation was done using data from the same hospital but collected at different times.

Information on environmental risk factors was not collected, and this may have created a gap in the risk factors of the studied population.

Despite these biases and limitations, the urgent need for a risk prediction model in providing relevant breast cancer control in developing societies such as North Cyprus outweighs the shortfalls.

\section{Conclusions}

Our results demonstrated that this newly developed breast cancer risk prediction model is a simple, cost-effective, and noninvasive tool for the identification of high-risk women in North Cyprus that can be eligible for a mammogram. It may serve as a gatekeeper for a mammogram and a radiation saving tool for low-risk women, by reducing unnecessary mammograms and thereby decreasing health costs. This model is suitable for the prediction of late on-set breast cancer risk and further studies on a larger study group, including environmental risk factors will be needed to improve the model.

Author Contributions: C.D.D. designed the work, collected, analyzed and interpreted the data and also drafted the manuscript. N.S. designed the work, analyzed and interpreted the data and revised the manuscript. All authors have read and agreed to the published version of the manuscript.

Funding: This research received no external funding.

Acknowledgments: Our gratitude goes to the participants for their time and willingness to respond to the interviews. Though names are numerous to be mentioned, we sincerely show our appreciation to the management 
and staff of the Cancer Center of Burhan Nalbantoglu Devlet Hastanesi, Lefkosa, North Cyprus, for their support and allowing us to access their database.

Conflicts of Interest: The authors declare no conflict of interest.

\section{References}

1. Parkin, D.M.; Bray, F.; Ferlay, J.; Pisani, P. Global cancer statistics, 2002. CA Cancer J. Clin. 2005, 55, 74-108. [CrossRef] [PubMed]

2. Bray, F.; Ferlay, J.; Soerjomataram, I.; Siegel, R.L.; Torre, L.A.; Jemal, A. Global Cancer Statistics 2018: GLOBOCAN estimates of incidence and mortality worldwide for 36 cancers in 185 countries. CA Cancer. J. Clin. 2018, 68, 394-424. [CrossRef] [PubMed]

3. de Sanjose, S.; Serrano, B.; Castellsague, X.; Brotons, M.; Munoz, J.; Bruni, L.; Bosch, F.X. Human papillomavirus (HPV) and related cancers in the Global Alliance for Vaccines and Immunization (GAVI) countries. A WHO/ICO HPV Information Centre Report. Vaccine 2012, 30, D1-83, vi.

4. Commission on Social Determinants on Health. Closing the gap in generation: Health equity through action on social determinants of health. Public Health 2008, 372, 1661-1669.

5. Torre, L.A.; Bray, F.; Siegel, R.L.; Ferlay, J.; Lortet-Tieulent, J.; Jemal, A. Global cancer statistics, 2012. CA Cancer J. Clin. 2015, 65, 87-108. [CrossRef] [PubMed]

6. Breast Cancer Facts \& Figures 2019-2020. Available online: https://www.cancer.org/content/dam/cancer-org/ research/cancer-facts-and-statistics/breast-cancer-facts-and-figures/breast-cancer-facts-and-figures-20192020.pdf (accessed on 7 July 2020).

7. Allemani, C.; Weir, H.K.; Carreira, H.; Harewood, R.; Spika, D.; Wang, X.S.; Bannon, F.; Ahn, J.V.; Johnson, C.J.; Bonaventure, A.; et al. Global surveillance of cancer survival 1995-2009: Analysis of individual data for 25,676,887 patients from 279 population-based registries in 67 countries (CONCORD-2). Lancet 2015, 385, 977-1010. [CrossRef]

8. Sankaranarayanan, R.; Swaminathan, R.; Brenner, H.; Chen, K.; Chia, K.S.; Chen, J.G.; Law, S.C.K.; Ahn, Y.-O.; Xiang, Y.B.; Yeole, B.B.; et al. Cancer survival in Africa, Asia, and Central America: A population-based study. Lancet Oncol. 2010, 11, 165-173. [CrossRef]

9. Riboli, E.; Norat, T. Epidemiological evidence of the protective effect of fruit and vegetable on cancer risk. Am. J. Clin. Nutr. 2003, 78, 559-569. [CrossRef]

10. Martinez-Gonzales, M.; Sanchez-Villegas, A. The emerging role of Mediterranean diets in cardiovascular epidemiology: Monosaturated fats, olive oil, red wine or the whole pattern? Eur. J. Epidemiol. 2004, 19, 9-13. [CrossRef]

11. Hincal, E.; Taneri, U.; Djamgoz, M.B. Cancer incidence in North Cyprus (1994-2004) relative to European rates. Asian. Pac. J. Cancer Prev. 2008, 9, 725-732.

12. Pervaiz, R.; Tulay, P.; Faisal, F.; Serakinci, N. Incidence of Cancer in the Turkish republic of northern Cyprus. Turk. J. Med. Sci. 2017, 47, 523-530. [CrossRef] [PubMed]

13. Cuzick, J. Breast cancer prevention in the developing world. Breast Cancer Res. 2010, 12, s9. [CrossRef] [PubMed]

14. Colditz, G.A.; Bohlke, K. Priorities for the primary prevention of breast cancer. CA Cancer J. Clin. 2014, 64, 186-194. [CrossRef]

15. Youlden, D.R.; Cramb, S.M.; Dunn, N.A.; Muller, J.M.; Pyke, C.M.; Baade, P.D. The descriptive epidemiology of female breast cancer: An international comparison of screening, incidence, survival and mortality. Cancer Epidemiol. 2012, 36, 237-248. [CrossRef]

16. Lauby-Secretan, B.; Scoccianti, C.; Loomis, D.; Benbrahim-Tallaa, L.; Bouvard, V.; Bianchini, F.; Striaf, K. Breast-cancer screening-Viewpoint of the IARC Working Group. N. Engl. J. Med. 2015, 372, 2353-2358. [CrossRef]

17. Sankaranarayanan, R.; Ramadas, K.; Qiao, Y.L. Managing the changing burden of cancer in Asia. BMC Med. 2014, 12, 3. [CrossRef] [PubMed]

18. Independent UK Panel on Breast Cancer Screening. The benefits and harms of breast cancer screening: An independent review. Lancet 1786.

19. WHO. WHO Position Paper on Mammography Screening; World Health Organization: Geneva, Switzerland, 2014. 
20. Niens, L.M.; Zelle, S.G.; Gutierrez-Delgado, C.; Pena, G.R.; Balarezo, B.R.H.; Stellar, E.R.; Rutten, F.F.H. Cost-effectiveness of breast cancer control strategies in Central America: The cases of Costa Rica and Mexico. PLOS ONE 2014, 9, e95836. [CrossRef]

21. Okonkwo, Q.L.; Draisma, G.; der Kinderen, A.; Brown, M.L.; de Koning, H.J. Breast cancer screening policies in developing countries: A cost-effectiveness analysis for India. J. Natl. Cancer Inst. 2008, 100, 1290-1300. [CrossRef]

22. Zelle, S.G.; Nyarko, K.M.; Bosu, W.K.; Aikins, M.; Niens, L.M.; Lauer, J.A.; Sepulveda, C.R.; Hontelez, J.A.C.; Baltussen, R. Costs, effects and cost-effectiveness of breast cancer control in Ghana. Trop Med. Int. Health 2012, 17, 1031-1043. [CrossRef] [PubMed]

23. Anderson, B.O.; Cazap, E.; El Saghir, N.S.; Yip, C.H.; Khaled,H.M.; Otero, I.V.; Adebamowo, C.A.; Badwe, R.A.; Harford, J.B. Optimisation of Breast Cancer Management in Low-Resource and Middle-Resource Countries: Executive Summary of the Breast Health Global Initiative Consensus, 2010. Lancet Oncol. 2011, 12, 387-398. [CrossRef]

24. Unger-Saldana, K. Challenges to the early diagnosis and treatment of breast cancer in developing countries. World J. Clin. Oncol. 2014, 5, 465-477. [CrossRef] [PubMed]

25. Denny, L.; de Sanjose, S.; Mutebi, M.; Anderson, B.O.; Kim, J.; Jeronimo, J.; Herrero, R.; Yeates, K.; Ginsburg, O.; Sankaranarayanan, R. Interventions to close the divide for women with breast and cervical cancer between low-income and middle-income countries and high-income countries. Lancet 2017, 389, 861-870. [CrossRef]

26. Kelsey, J.L.; Bernstein, L. Epidemiology and prevention of breast cancer. Annu. Rev. Public Health 1996, 17, 47-67. [CrossRef] [PubMed]

27. Welsh, M.L.; Burst, D.S.; Bowles, A.E.J.; Anderson, M.L.; Elmore, J.G.; Li, C.I. Population-based estimates of the relation between breast cancer risk, tumour subtype and family history. Breast Cancer Res. Treat 2009, 114, 549-558. [CrossRef]

28. Brandt, A.; Bermejo, J.; Sundquist, J.; Hemminki, K. Age of onset in familial breast cancer as background data for medical surveillance. Br. J. Cancer 2010, 102, 42-47. [CrossRef] [PubMed]

29. McCormack, V.A.; Silva, d.S.I. Breast Density and parenchymal patterns as markers of breast cancer risk: A meta-analysis. Cancer Epidemiol. Biomarkers Prev. 2006, 15, 1159-1169. [CrossRef]

30. Amir, E.; Freedman, O.C.; Seruga, B.; Evans, D.G. Assessing women at high risk of breast cancer: A review of risk assessment models. J. Natl. Cancer Inst. 2010, 102, 680-691. [CrossRef]

31. Antoniou, A.C.; Hardy, R.; Walker, L.; Evans, D.G.; Shenton, A.; Pichert, G.; Izatt, L.; Rose, S.; Douglas, F.; Eccles, D.; et al. Predicting the likelihood of carrying a BRCA1 or BRCA2 mutation: Validation of BOADICEA, BRCAPRO, IBIS, Myriad and the Manchester scoring system using data from UK genetics clinics. J. Med. Genet. 2008, 45, 425-431. [CrossRef]

32. Rockhill, B.; Spiegelman, D.; Byrne, C.; Hunter, D.J.; Colditz, G.A. Validation of the Gail et al. model of breast cancer risk prediction and implications for chemoprevention. J. Natl. Cancer Inst. 2001, 93, 358-366. [CrossRef]

33. Antoniou, A.C.; Cunningham, A.P.; Peto, J.; Evans, D.G.; Lalloo, F.; Narod, S.A.; Risch, H.A.; Eyfjord, J.E.; Hopper, J.L.; Southey, M.C.; et al. The BOADICEA model of genetic susceptibility to breast and ovarian cancers: Updates and extensions. Br. J. Cancer 2008, 98, 1457-1466. [CrossRef] [PubMed]

34. Humphrey, L.L.; Helfand, M.; Chan, B.K.; Woolf, S.H. Breast cancer screening: A summary of the evidence for the U.S. Preventive Services Task Force. Ann. Intern. Med. 2002, 137, 347-360. [CrossRef] [PubMed]

35. Costantino, J.P.; Gail, M.H.; Pee, D.; Anderson, S.; Redmond, C.K.; Benichou, J.; Wieand, H.S. Validation studies for models pro-jecting the risk of invasive and total breast cancer incidence. J. Natl. Cancer Inst. 1999, 91, 1541-1548. [CrossRef]

36. Schonfeld, S.J.; Pee, D.; Greenlee, R.T.; Hartge, P.; Lacey Jr, J.V.; Park, Y.; Schatzin, A.; Visvanathan, K.; Pfieffer, R.M. Effect of changing breast cancer incidence rates on the calibration of the Gail model. J. Clin. Oncol. 2010, 28, 2411-2417. [CrossRef] [PubMed]

37. Pickle, L.M.; Johnson, K.A. Estimating the long-term probability of developing breast cancer. J. Natl. Cancer Inst. 1989, 81, 1854-1855. [CrossRef] [PubMed]

38. Harrell, F.E., Jr.; Lee, K.L.; Mark, D.B. Multivariable prognostic models: Issues in developing models, evaluating assumptions and adequacy, and measuring and reducing errors. Stat. Med. 1996, 15, 361-387. [CrossRef] 
39. Schumacher, M.; Hollander, N.; Sauerbrei, W. Resampling and cross-validation techniques: A tool to reduce bias caused by model building? Stat. Med. 1997, 16, 2813-2827. [CrossRef]

40. Terry, M.B.; Liao, Y.; Whittemore, A.S.; Leoce, N.; Buchsbaum, R.; Zeinomar, N.; Dite, G.S.; Chung, W.K.; Knight, J.A.; Southey, M.C.; et al. 10-year performance of four models of breast cancer risk: A validation study. Lancet Oncol. 2019, 20, 504-517. [CrossRef]

41. Lichtenstein, P.; Holm, N.V.; Verkasalo, P.K.; Lliadou, A.; Kaprio, J.; Koskenvuo, M.; Pukkala, E.; Skytthe, A.; Hemminki, K. Environmental and Heritable Factors in the Causation of Cancer-Analyses of Cohorts of Twins from Sweden, Denmark, and Finland. N. Engl. J. Med. 2000, 343, 78-85. [CrossRef]

42. Barnard, M.; Boeke, C.; Tamimi, R. Established breast cancer risk factors and risk of intrinsic tumor subtypes. Biochem. Biophys. Acta 2015, 1856, 73-85. [CrossRef]

43. Collaborative Group on Hormonal Factors in Breast Cancer. Familial breast cancer: Collaborative reanalysis of individual data from 52 epidemiological studies including 58,209 women with breast cancer and 101,986 women without the disease. Lancet 2001, 358, 1389-1399. [CrossRef]

44. Pharoah, P.D.; Day, N.E.; Duffy, S.; Easton, D.F.; Ponder, B.A. Family history and the risk of breast cancer: A systematic review and meta-analysis. Int. J. Cancer 1997, 71, 800-809. [CrossRef]

45. Turnbull, C.; Rahman, N. Genetic Predisposition to Breast Cancer: Past, Present, and Future. Ann. Rev. Genomics Hum. Genet. 2008, 9, 321-345. [CrossRef]

46. Kaminska, M.; Ciszewski, T.; Lopacka-Szatan, K.; Miotla, P.; Staroslawska, E. Breast cancer risk factors. Prz. Menopauzalny 2015, 14, 196-202. [CrossRef] [PubMed]

47. Sun, Y.S.; Zhao, Z.; Yang, Z.N. Risk factors and preventions of breast cancer. Int. J. Biol. Sci. 2017, 13, 1387-1397. [CrossRef] [PubMed]

48. Singletary, S.E. Rating the risk factors for breast cancer. Ann. Surg. 2003, 237, 474-482. [CrossRef]

49. Howell, A.; Anderson, A.S.; Clarke, R.B. Risk determination and prevention of breast cancer. Breast Cancer Res. 2014, 16, 446. [CrossRef]

50. Anothaisintawee, T.; Wiratkapun, C.; Lerdsitthichai, P. Risk factors of breast cancer: A systematic review and meta-analysis. Asia Pac. J. Public Health 2013, 25, 368-387. [CrossRef] [PubMed]

51. Ozsoy, A.; Barca, N.; Dolek, B.A. The relationship between breast cancer and risk factors: A single-center study. Eur. J. Breast Health 2017, 13, 145-149. [CrossRef]

52. McTiernan, A. Behavioral risk factors in breast cancer: Can risk be modified? Oncologist 2003, 8, 326-334. [CrossRef]

53. Patterson, R.E.; Cadmus, L.A.; Emond, J.A.; Pierce, J.P. Physical activity, diet, adiposity and female breast cancer prognosis: A review of the epidemiologic literature. Maturitas 2010, 66, 5-15. [CrossRef] [PubMed]

54. Rock, C.L.; Demark-Wahnefried, W. Can lifestyle modification increase survival in women diagnosed with breast cancer? J. Nutr. 2002, 132, 3504S-3507S. [CrossRef] [PubMed]

55. Yang, X.R.; Sherman, M.E.; Rimm, D.L. Differences in risk factors for breast cancer molecular subtypes in a population-based study. Cancer Epidemiol. Biomark Prev. 2007, 16, 439-443. [CrossRef] [PubMed]

56. Anderson, W.F.; Rosenberg, P.S.; Prat, A.; Perou, C.M.; Sherman, M.E. How many etiological subtypes of breast cancer: Two, three, four, or more? J. Natl. Cancer Inst. 2014, 106, dju165. [CrossRef] [PubMed]

57. Siegel, R.; Ma, J.; Zou, Z.; Jemal, A. Cancer statistics. CA Cancer. J. Clin. 2014, 64, 9-29. [CrossRef]

58. Nystrom, L.; Andersson, I.; Bjurstam, N.; Frisell, J.; Nordenskjold, B.; Rutqvist, L.E. Long-term effects of mammography screening: Updated overview of the Swedish randomised trials. Lancet 2002, 359, 909-919. [CrossRef]

59. Leach, M.O.; Boggis, C.R.; Dixon, A.K.; Easton, D.F.; Eeles, R.A.; Evans, D.G.; Gilbert, F.J.; Griebsch, I.; Hoff, R.J.; Kessar, P.; et al. Screening with magnetic resonance imaging and mammography of a UK population at high familial risk of breast cancer: A prospective multicentre cohort study (MARIBS). Lancet 2005, 365, 1769-1778.

60. Kriege, M.; Brekelmans, C.T.; Boetes, C.; Besnard, P.E.; Zonderland, H.M.; Obdeijn, I.M.; Manoliu, R.A.; Kok, T.; Peterse, H.; Madeleine, M.A.; et al. Efficacy of MRI and mammography for breast-cancer screening in women with a familial or genetic predisposition. N. Engl. J. Med. 2004, 351, 427-437. [CrossRef]

61. Le-Petross, H.T.; Whitman, G.J.; Atchley, D.P.; Yuan, Y.; Gutierrez-Barrera, A.; Hortobagyi, G.N.; Litton, J.K.; Arun, B.K. Effectiveness of alternating mammography and magnetic resonance imaging for screening women with deleterious BRCA mutations at high risk of breast cancer. Cancer 2011, 117, 3900-3907. [CrossRef] 
62. Saslow, D.; Boetes, C.; Burke, W.; Harms, S.; Leach, M.O.; Lehman, C.D.; Morris, E.; Pisano, E.; Schnall, M.; Sener, S.; et al. American Cancer Society guidelines for breast screening with MRI as an adjunct to mammography. CA Cancer J. Clin. 2007, 57, 75-89. [CrossRef]

63. A Guide for Countries Joining the m-Health Program. Available online: https://www.who.int/nmh/events/ 2012/mhealth_guide.pdf (accessed on 7 July 2020).

64. Reiser, B. Measuring the effectiveness of diagnostic markers in the presence of measurement error through the use of ROC curves. Stat. Med. 2000, 19, 2115-2129. [CrossRef]

C 2020 by the authors. Licensee MDPI, Basel, Switzerland. This article is an open access article distributed under the terms and conditions of the Creative Commons Attribution (CC BY) license (http://creativecommons.org/licenses/by/4.0/). 